\title{
Testing the Weak Form of Efficient Market Hypothesis in Nigerian Capital Market
}

\author{
Mayowa Gabriel Ajao (Corresponding author) \\ Dept of Banking and Finance, Faculty of management Sciences \\ University of Benin, Benin-City, Edo-state, Nigeria \\ E-mail: mayourwah@yahoo.com, ajao.mayowa@uniben.edu \\ Richard Osayuwu \\ Dept of Banking and Finance, Faculty of management Sciences \\ University of Benin, Benin-City, Edo-state, Nigeria
}

Received: March 22, 2012

Accepted: April 25, 2012

Published: May 15, 2012

doi:10.5430/afr.v1n1p169

URL: http://dx.doi.org/10.5430/afr.v1n1p169

\begin{abstract}
This study aims at testing the weak form of efficient market hypothesis in the Nigerian capital market. The scope of the study consist of all securities traded on the floor of the Nigerian Stock Exchange and the month end value of the All Share Index from $2001-2010$ constitute the data analyzed. The serial correlation technique of data analysis was used to test for independence of successive price movement and the distributive pattern while runs test was used to test for randomness of share price movement. The result of the serial correlation shows that the correlation coefficients did not violate the two-standard error test. Furthermore, the Box-Ljung statistic shows that none of the serial correlation coefficients was significant and the Box pierce Q statistics shows that the overall significance of the serial correlation test was poor while the result of the distribution pattern shows that stock price movements are approximately normal. on the basis of this findings, we conclude that successive price changes of stocks traded on the floor of the Nigerian Capital Market are independent and random therefore, the Nigerian Capital Market is efficient in the weak-form.
\end{abstract}

Keywords: Efficiency, Randomness, Independence, Share price, All share index

\section{Introduction}

The efficiency of stock markets has been a major area of research in financial economics, particularly as it pertains to stock markets of developing economies (Rapuluchukwu, 2010). This is because of the implication of market efficiency to the functioning of the capital market; especially as it concerns investors' returns and thus stimulation of investor's interest in market activities. It is believed that the behaviour of stock prices is explained by the behaviour of investors. Stock market forecasting is marked more by its failure than by its successes since stock prices reflect the judgments and expectations of investors based on information available (Aguebor, Adewole and Maduegbuna, 2010). Remarkably, efforts have been made to apply econometric techniques of model building in the prediction of stock prices in a bid to demonstrate that the market fluctuations are essentially unpredictable (Brealey and Myers, 1996; and Brummelhuis, 2005). Fama and French (1988) have argued that there are long-term pattern in stock prices with several years of upswing followed by more sluggish periods. According to Fama $(1965 ; 1995)$, a stock market where successive price changes in individual securities are independent is by their definition, a random walk market. Specifically, stock prices following a random walk imply that the price changes are as independent of one another as the gains and losses. The independence assumption of the random walk hypothesis is valid as long as knowledge of the past behaviour of the series of price changes cannot be used to increase expected gains (Aguebor, etal 2010). More specifically, if successive price changes for a given security are independent, then there is no problem in timing purchases and sales of the security. A simple policy of buying and holding the security will be as good as any more complicated mechanical procedure for timing purchase and sales (Fama, 1965; 1995).

The stock market, more than ever before, is increasingly becoming one of the most popular investments outlet in recent times due to its high returns and the market has gradually become an integral part of the global economy to the extent that any fluctuation in this market influences personal and corporate financial lives as well as the economic health of a 
country. Furthermore, the stock market is crucial to the nation's economic development because it, among other functions, performs the vital function of financial intermediation in the economy by taking money from the surplus units in the economy and channelling same to the deficit units in the economy. However, the ability of the stock market to perform its role effectively and assure investors of fair returns is contingent on the extent to which it can be said to be efficient. This underscores the essence of studies that seek to test stock market efficiency. If a market is not efficient then, behaviourally, stocks that outperform the market will inspire positive sentiments among investors while stocks that under-perform may induce panic. Consequently, stocks that under-perform at any given point in time relative to the market are more sensitive to new information (Lulia, 2009). In other words, there is a negative relationship between the measure of price sensitivity to news and the stock's performance relative to the market. On the other hand, panic drives the price sensitivity to new information than the thrill of investing in a high-return stock does, or simply yet, the downside hurts investors more than the upside helps them (Lulia, 2009).

In an active market made up of knowledgeable investors, securities will be fairly priced to reflect all available information (Fama, 1965). If a market is efficient then the security price, at any given time, will fully incorporate all available information and thus make it impossible for any investor to outperform the market. This study therefore aims to test the weak form of efficient market hypothesis in the Nigerian capital market with a view to determining whether the Nigerian capital market is efficient or not; and to determining whether the Nigerian capital market provides investors with fair returns on their investments or otherwise.

The main objective of the study is to test the weak form of the efficient market hypothesis in the Nigerian capital market. The specific objectives are to determine: whether the movements in the prices of stocks traded on the floor of the Nigerian stock exchange are independent and whether the movements in the prices of stocks traded on the floor of the Nigerian stock exchange are random. The scope of this study consists of all securities trade on the floor of the Nigerian stock Exchange within the period 2001 -2010. Since the study is concerned with movements in stock prices, the All-Share Index; which is the aggregation of the price gains and losses for a given period was used. Consequently, the month-end values of All-Share Index for the period 2001 - 2010 constitute the data for this study.

\section{Review of Related Literatures}

The investment process provides an opportunity for firms to finance their operations and thus ensure that they do not go bankrupt due to paucity of funds. The central problem of man as revealed by economics is the paucity of resources vis-à-vis the demands for these resources. This underscores the need for efficient allocation of resources. In order for the investor to allocate resources efficiently, there is need for thorough security analysis, selection, supervision, and rationalization (Herman, 2001). Thorough security analysis will predispose the investors to make the adequate decision regarding the appropriate security or securities to invest in, as well as when to invest in the securities, with a view to maximizing their returns. But the ability of the investors to enhance their returns through security analysis is a function of the nature of the capital market in which they operates.

Security Analysis concerns the evaluation of securities with a view to determining which, when, and what quantity to buy as well as which, when and what quantity to sell. Traditional security analysis involves the identification of undervalued securities to buy and overvalued securities to sell by security analysts (Fisher and Jordan, 2005). However, modern day thinking, strongly influenced by the efficient market hypothesis (sometimes called the Random walk theory) questions the validity of, or benefit to be derived from traditional security analysis. Consequently, modern security analysis is the entire process of estimating return and risk for individual securities. The process of modern security analysis sees only indirect benefits resulting from the analyst's risk-return calculations (Fisher and Jordan, 2005). Basically, traditional security analysis is done to determine the intrinsic value of securities. On the basis of the estimated intrinsic value and the market price, the analyst will be able to determine whether the security is currently undervalued (in which case the investor will be advised to buy) or whether the security is overvalued, in which case, a sell option is appropriate. The major thrust of security analysis is to examine the industries' securities and those of individual companies with a view to developing value and return expectations for securities and thus distinguish over-priced securities from under-priced ones. Overpriced ones attract a sell option while under-priced ones attract a buy option. To this end, security analysis seeks to assist investors to optimize returns for their investments. There are five major theories that seek to explain stock price behaviour; they are - the fundamental school; the technical school; Macroeconomic Hypothesis School, the Behavioural School; and the Efficient Market hypothesis. This study however focused on the efficient market hypothesis.

\subsection{Efficient Market hypothesis}

The Efficient Market Hypothesis was first published by Louis Bachelier, a French mathematician, in his $\mathrm{PhD}$ dissertation "The Theory of Speculation" however, his work was largely ignored until the 1950s. Efficient Market 
Hypothesis, as a prominent theoretical position, evolved in the mid-1960s from the PhD Dissertation of Eugene Fama. He persuasively made the argument that in an active market, which includes many well-informed and intelligent investors, securities will be appropriately priced, and reflect all available information (Investor Home, 2008). Thus, if a market is efficient, no information or analysis can be expected to result in the out-performance of an appropriate benchmark. Both the "technical" and "fundamental" analysts have been challenged by scholars who subscribe to the efficient market hypothesis. The "efficient market hypothesis" posits that investors adjust securities prices rapidly to reflect the effect of new information (Maku and Atanda, 2009). Proponents of the efficient market hypothesis argue that stock prices are essentially random and therefore, there is no chance for profitable speculation in the stock market. The efficient market hypothesis is based on the assumption that share prices follow a random walk and successive price changes are independent of each other (Rapuluchukwu, 2010). This implies that no individual can make supernormal profit from trading in securities since the share prices are not mis-priced in any form of systematic or predictable way (Mishra, 2009). Samuels and Wilkes (1981) defined an efficient market as one in which prices of traded securities always fully reflect all publicly available information concerning those securities. Furthermore, Samuels and Wilkes (1981) identified necessary conditions for an efficient market to include accurate signals for investors' choices. This implies that today's price which reflects all publicly available information is the best estimate of tomorrow's price (Osaze, 2000). Reily (1989) sees an efficient market as one in which security prices adjust rapidly to the infusion of new information and current stock prices fully reflect all available information, including the risks involved. Thus, a stock market is said to be efficient if information is widely and cheaply available to investors such that share prices are fair. A fair share price is one which reflects all available, relevant, and ascertainable information in the market. An Efficient Stock market results from the presence of numerous, rational profit maximizing investors, who are actively competing with one another.

Malkiel (2003) further reiterated that irrespective of the kind of analysis, whether technical analysis (study of past stock prices to predict future prices) or fundamental analysis (study of economy, industry and company related factors), no analyst can make abnormal profit; hence, market prices will reflect best estimates for the risk and expected returns from the assets based on all the information available as at the time of reference (Gupta and Basu, 2007). Information reflected by the current stock prices includes information particular to the company offering the shares and information general to the market. All these information follow a random order in their occurrences and are reflected by the share prices, therefore, no person can accurately predict their occurrence. An interesting feature of the random walk hypothesis is the persistence of random shocks. Early empirical tests of the random-walk hypothesis by scholars like Fama (1965) showed significant departures from randomness; and were both inconclusive and insufficient (Maku and Atanda, 2009). The major thrust of the Random Walk Hypothesis is that the current prices of stocks already fully reflect all the information that is contained in the historical sequence of prices. Consequently, forecasting future stock prices through the examination of the historical sequence of prices does not yield any benefit to the investors. If this random walk hypothesis is true, then, it is a direct repudiation of the technical analysis. If there is no value in studying past prices and past price changes, then, there is no value in technical analysis (Fisher and Jordan, 2005). Jensen (1978) defines the efficient market as one where there is a zero-competitive equilibrium condition and it is impossible to make economic profit (the risk adjusted returns net of all cost) by trading on the available set of information present in time $t$. The information present at time $t$ is all the information presently reflected in the current stock prices. The implication is that the stock price at time $t$ is as a result of all the available information $t$ and stock price in time $t+1$ reflect all available information at $t+1$ because when information infiltrates into the market it spreads quickly and it is incorporated into the stock prices immediately (Malkiel, 2003). Therefore, the present stock price cannot accurately be used to predict the future stock price. The implications of the Efficient Market Hypothesis are profound. Most individuals who buy and sell securities (stocks in particular) do so under the assumption that the securities that they are buying are worth more than the price that they are paying, while the securities that they are selling are worth less than the selling price. But if markets are efficient and current price fully reflect all information, then, buying and selling securities in an attempt to outperform the market will effectively be a game of chance rather than skill (Investor Home, 2008). In view of the foregoing, the Efficient Market Hypothesis (EMH) argues that the future price of a security, given today's set of information, is equal to today's price compounded at some desired return that is commesurate with the risk associated with the security. There are basically three broad categories of the efficient market hypothesis. - the Weak Form, the Semi-Strong Form, and the strong Form. One might more readily understand the distinctions and variations of the various forms of the more general efficient market hypothesis by viewing it and its variations as lying on a continuum, with the so-called Random Walk Model at one end (Fisher and Jordan, 2005). 


\subsection{Empirical literatures}

Though no stock market is generally believed to be strong-form efficient, most early tests of stock markets in industrialised countries have typically been unable to reject null hypotheses of semi-strong and weak-form efficiency [Fama, 1970]. Some recent studies, however, have tested for the semi-strong and weak-form efficiency in developing countries, focusing primarily on the emerging Asian economies, the Latin American markets, African and the Middle East. Chan, Gup, and Pan [1992], for example, use unit root tests that show weak-form stock market efficiency in Hong Kong, South Korea, Singapore, and Taiwan. Liu, Song and Romilly [1997] find that both the Shanghai and Shenzhen Chinese stock market indices are characterised by a random walk and are thus weak-form efficient, although cointegration tests indicate joint inefficiency between the two markets, i.e. past returns from one market can be used to predict returns in another. Groenewold and Ariff [1998], carrying out unit-root tests on a set of ten stock markets in the Asia/Pacific region, find some evidence of violations of weak-form efficiency, yet they find the violations fairly mild in most markets. Ormos, Mihaley (2002) empirically tested the efficiency of Hungarian Capital Market in its semi-strong and strong form. The study focused to examine whether the Hungarian Capital Market was efficient in the semi-strong form. The investigation was based on the capital market data over the period 1991 to 2000, which was analyzed by employing event study. The study concluded that strong form of efficiency of capital market does not completely hold true, thereby supporting that Hungarian Capital Market is semi-strong form efficient.. Hadi (2006) threw light on the types of Efficient Market Hypothesis. He undertook a detailed research that tested weak, semi-strong and strong forms of market efficiency. It is observed that accounting based research generally assumes that market is efficient in semi-strong form. The reason behind this is that the financial reports are considered public information once they have been released in the market. He provided empirical evidence from the Jordanian market, which suggested that the security market reacted with mixed signals on releasing profitability, liquidity and solvency information.

In a test on Latin American stock markets, Urrutia [1995] finds that these markets generally fail to pass tests of weak-form efficiency in that they do not follow a random walk. However, he finds them weak-form efficient by means of a runs test, implying that investors are unlikely to be able to develop trading strategies to earn excess returns. El-Erian and Kumar [1995] find some departures from weak-form efficiency in Middle Eastern stock markets, but emphasise the serial dependence is sufficiently weak that it likely has little value in predicting future prices. Their finding is consistent with that of Butler and Malaikah [1992], who find statistically significant autocorrelation in the stock markets of Kuwait and Saudi Arabia.

Iqbal and Mallikarjunappa, (2007) tested market reaction to quarterly earnings announcement of 149 companies listed on the Bombay Stock Exchange for September 2001 by employing both parametric and nonparametric tests. It is observed that during event window, runs test are not significant at $5 \%$ level, which signifies that abnormal returns occur randomly. On the other hand, t-test rejects the existence of abnormal returns on daily basis, which provides an opportunity to beat the market and earn abnormal returns. The study concludes that Indian stock market is not efficient in semi-strong form. Yalama, Abdullah and Selik, Sibel (2008) investigated semi-strong form efficiency in Istanbul Stock Exchange Market (ISE-100), Foreign Exchange Market (FEM) and Inter-bank Money Market (IMM) in respect to changes in Currency and Circulation (CIC). The data consist of the daily frequency over the period 1990-2008 which was analyzed by employing Toda Yamamoto Causality method. The study concludes that there is the causality relationship running from CIC to FEM and CIC to IMM. However, there is no causality relationship running from CIC to ISE-100. This result implies that in Turkey, money market is semi-strong form efficient while capital market is not.

Two pieces of research that focus specifically on African markets are Dickinson and Muragu [1994] and Olowe [1999]. Dickinson and Muragu create a database of weekly prices over ten years of the 30 most actively traded equities on the Nairobi Stock Exchange. They fail to find evidence inconsistent with weak-form efficiency in the stock exchange by means of both runs tests and Q-test statistics, but suggest that a number of studies must be carried out on any market using a variety of methodologies to draw firm conclusions about weak-form efficiency. Olowe [1999] carries out tests using monthly data on 59 randomly selected securities from 1981-92 on the Nigerian Stock Exchange. He finds the Nigerian market to conform to weak-form efficiency in joint Q-tests of partial autocorrelation coefficients for ten lags in the return data, though he argues that poor informational flows and inefficient communications systems cast doubts on the ability of the market to pass higher hurdles of efficiency.

Besides Olowe (1999) study, other empirical tests of the Weak form of the Efficient Market hypothesis have been conducted on the Nigerian Stock Exchange by Ekechi (2002), Inegbedion (2009), Aguegbo, etal (2010) and Rapuluchukwu (2010). Results of the various tests are not consistent. While the studies conducted by Odukwe (1983), Ayadi (1983), and Rapuluchukwu (2010) concluded that the Nigerian Stock Market is efficient in the weak form, those conducted by Ekechi (2002) Inegbedion (2009), as well as Aguegbo, etal (2010), indicate that the Nigerian Stock 
Market is not efficient in the Weak form. But it is pertinent to note that all the studies that showed that the Nigerian Stock Market is Efficient in the weak form utilized the All-Share Index of the Nigerian Stock Exchange, which is the aggregation of price gains and losses for all the securities traded on the floor of the Nigerian Stock Exchange, in their analysis; while the studies that showed that the market was not efficient in the weak form used a sample of selected securities

\section{Research Methodology}

This study examines the price of shares traded on the floor of the Nigerian stock exchanges for a period of time and observes changes in the shares prices with a view of determining the efficiency of the market, consequently, it is a longitudinal survey. This is consistent with Agbonifoh and Yomere,(2010) who see longitudinal survey as one which studies a phenomenon, event or group over a period of time. Specifically, a careful description of the model specification as well as the method of data analysis is presented below.

\subsection{Hypotheses}

In view of the problem definition of the study, the following hypotheses (stated in the null form) were tested.

1) The Movements in the prices of stocks traded on the floor of the Nigeria stock exchange are not independent;

2) The Movements in the prices of stocks traded on the floor of the Nigeria stock exchange are not random.

\subsection{Data Analysis Method}

The research data were analyzed using descriptive and inferential statistics distribution patterns (test for normality of distribution of price changes), which is a measure of the randomness of price changes, serve as the descriptive statistics while inferential tests consist of testing the All-share index of the Nigerian stock exchange, which measure changes in the prices of shares traded on the floor of the Nigerian stock exchange, for independence (using serial correlation test) and randomness(using runs test).

\subsubsection{Test for independence of data.}

The serial correlation test was used to test for independence of successive stock price. Otherwise known as autocorrelation, serial correlation is a non parametric test for independence. Specifically, it measures the relationship between successive values of a given variable.

A Stochastic process is said to be strictly stationary if its properties are unaffected by a change in time origin. This implies that the joint probability distribution associated with $\mathbf{N}$ observations $Z_{\mathrm{t} 1}, Z_{\mathrm{t} 2} \ldots ., Z_{\mathrm{tn}}$ is the same as that associated with $\mathbf{n}$ observations $Z_{\mathrm{t} 1+\mathrm{k}}, \mathrm{t}_{2+\mathrm{k}} \ldots . Z_{\mathrm{tn}+\mathrm{k}}$ made at times $\mathrm{t}_{1+\mathrm{k}}, \mathrm{t}_{2+\mathrm{k}} \ldots . \mathrm{t}_{\mathrm{n}+\mathrm{k}}$. The serial correlation of $\mathbf{N}$ observation at lag $\mathrm{k}$ is given by.

$$
\begin{aligned}
& R_{k}=\frac{\sum[(z t-u)(z t+k-u)]}{\sqrt{\left[(z t-u) 2 \sum\left(Z_{t}+k-u\right) 2\right]}} \\
& \text { i.e. } \mathrm{R}_{\mathrm{K}}=\frac{\operatorname{COV}\left(Z_{t}, Z_{t+k}\right)}{r Z_{t, r} Z_{t+k}}
\end{aligned}
$$

And $-1 \leq \mathrm{R}_{\mathrm{K}} \leq 1$ in line with Fama (1990) two control limits was computed using the estimates $-2 \mathrm{rp}<\mathrm{R}<2 \mathrm{rp}$. If the serial correlation estimates exceed the test limits above, the distribution of price would be termed not normal. That is, current prices are good indicators of future stock price movements.

\subsubsection{Test for significance of $P$, the coefficient of serial correlation.}

The Ljung- box test was used to test for significance of the serial correlation test for the individual lags while the Box-pierce (Q) test was used to test for significance of R, the serial correlation coefficient.

Here, $\mathrm{Q}=\mathrm{n} \sum(\mathrm{ri})^{2} 2 \mathrm{X}^{2} \mathrm{M}$ where

$\mathrm{Q}=$ box - pierce statistics;

$\mathrm{Ri}=$ serial correlation coefficient of the all-share index for different lags;

$\mathrm{X}^{2} \mathrm{n}=$ tabulated (critical) value of the chi-square statistic with $\mathrm{n}$ degrees of freedom;

$\mathrm{N}=$ minimum number of lags; and number of data point, observations in the sample,

\subsubsection{Test For Randomness Of Stock Prices}

Test for randomness will be achieved through distribution patterns and Runs tests. 
Distribution Patterns: This test involves plotting proportionate price changes to determine whether the shape conforms to the normal distribution, if it does then the share price changes can be said to be random;

Runs Test: This $\mathrm{Z}$ test will be used to test for randomness of data,

$\mathrm{Z}=\frac{\mathrm{R}+0.5+\mathrm{R}}{\mathrm{SR}}$

Where $R=\frac{2 N_{1} N_{2}}{N_{1}+N_{2}}+1$ mean number of price changes; and

$S R=\sqrt{\frac{2 N_{1} N_{2}\left(2 N_{1} N_{2}-N_{1}-N_{2}\right)}{\left(N_{1}+N_{2}\right) 2\left(N_{1}+N_{2}-1\right)}}$

Where $\mathrm{N}_{1}=$ number of positive price changes; $\mathrm{N}_{2}=$ number of negative price change; and $\mathrm{SR}=$ standard deviation of the distribution of the number of price changes.

\section{Presentation and Analysis of Rsesults}

In this section, the relevant research data, which consist of changes in the prices of all the shares listed on the floor of the Nigerian Stock Exchange, measured by the All-Share Index(Table I), were examined. The data were analyzed, after adjustment for stationarity by integration (differencing) of order one. Three types of tests were conducted:

- The serial (auto) correlation test - this was used to test for independence of the Movement (Changes) in the prices of

shares traded on the floor of the Nigerian Stock Exchange;

- The Runs test; which was done to test for randomness of the stock price movements; and

- Distribution Pattern, which was used to further test for randomness of the distribution of the stock price changes.

In addition to the above, the two standard error test, Ljung- Box, and the Box-Pierce test were used to test for significance of the serial correlation coefficients. On the basis of the series of tests conducted, the research inferences were made.

\subsection{Test of Hypotheses}

Ho: Successive changes in the prices of shares traded on the floor of the Nigerian Stock Exchange are independent. i.e $\rho=0$

$\mathrm{Ha}_{1}$ : Successive changes in the prices of shares traded on the floor of the Nigerian Stock Exchange are not independent. i.e $\rho \neq 0$

\section{BOX-PIERCE TEST (Q)}

$\mathrm{Q}=\mathrm{n} \sum \mathrm{r}_{\mathrm{i}}^{2} \sim \mathrm{m}$

Here, $\mathrm{n}=120=$ number of data points;

$r_{i}=$ serial correlation coefficient for the $i^{\text {th }}$ lag; and

$\mathrm{m}=$ number of lags.

Therefore, $\mathrm{Q}=120\left[(0.066)^{2}+(-0.036)^{2}+(-0.058)^{2}+(-0.045)^{2}+(-0.065)^{2}+(0.097)^{2}+(-0.175)^{2}+(.027)^{2}+(-0.139)^{2}+\right.$ $\left.(-0.084)^{2}+(-0.076)^{2}+(0.087)^{2}+(0.046)^{2}+(0.068)^{2}+(0.107)^{2}+(0.064)^{2}\right]=120 \times 0.118148=14.17776$

$$
\mathrm{m}={ }_{0.05,16}=26.3 \text {. }
$$

Results of the Box Pierce Q statistic indicate that the overall significance of the serial correlation test is poor since the calculated value of the Box Pierce Q is less than the tabulated value. The implication is that we cannot reject Ho. In other words, it is reasonable to conclude, at the ninety five percent (95\%) confidence level that the changes in the prices of shares traded on the floor of the Nigerian stock Exchange are independent. Results of the autocorrelation test indicate that the autocorrelation coefficients did not violate the two standard error test (see appendix). Furthermore, the Box-Ljung statistic indicates that none of the autocorrelation coefficients was significant since none of the asymptotic significant probabilities was less than 0.05 , the assumed level of significance. Consequently, we do not reject the null hypothesis $\left(\mathrm{HO}_{1}\right)$. To this end, we may conclude at the ninety five percent $(95 \%)$ confidence level that successive price changes for shares traded on the floor of the Nigerian Stock Exchange are independent.

$\mathbf{H o}_{2}$ : Successive changes in the prices of shares traded on the floor of the Nigerian Stock Exchange are random 
$\mathrm{Ha}_{2}$ : Successive changes in the prices of shares traded on the floor of the Nigerian Stock Exchange are not random.

Results in table II indicate that the calculated value of the $\mathrm{Z}$ test statistic for the runs test is -1.748 with an associated asymptotic significant probability associated with of 0.081 . Consequently, at a significant level of five percent (5\%) we do not reject the null hypothesis. We may thus conclude at the ninety five percent $(95 \%)$ confidence level that the movements in the price of shares traded on the floor of the Nigerian Stock Exchange are random. In the same vein, the results of the Distribution Pattern of Stock Price Movements in the Nigerian Stock Exchange is approximately normal, thus indicating that changes in the prices of shares traded on the floor of the Nigerian Stock Exchange are random. This is consistent with the results of the runs test. In view of the results of the two hypotheses, which suggest that prices of the shares traded on the floor of the Nigerian stock exchange are both independent and random, it is evident that the Nigerian Stock Exchange is efficient in the weak form.

\section{Findings}

A careful examination of the serial correlation coefficients of the changes in the prices of the securities traded in the Nigerian stock Exchange for the sixteen (16) lags shows that none of them exceeded the two- standard error limit based on the standard errors computed from the outputs of serial correlation coefficients. The implication is that the serial correlation coefficients are not significant, thus suggesting that the changes in the prices of shares traded on the floor of the Nigerian stock exchange are independent. Furthermore, the Box-Ljung test for significance of the serial correlation coefficients shows that none of the asymptotic significant probabilities is less than 0.05 , thus suggesting that none of the serial correlation coefficients is significant. Again, the implication is that the changes in the prices of shares traded on the floor of the Nigerian stock exchange are not serially correlated and are thus independent. Lastly, the Box-pierce test for the overall significance of the serial correlation coefficients was not significant at the $5 \%$ level, thus indicating that the serial correlation coefficients, taken together, are all not significant. This further consolidates the results of the two-standard error tests and Box-Ljung test.

In testing for randomness of the changes in the prices of stocks, the study utilized distribution patterns and runs test. An examination of the distribution patterns of stock price changes shows that the pattern is approximately normal, thus suggesting that the changes in the prices of stocks traded on the floor of the Nigerian stock exchange is random. The runs test for randomness of price changes revealed that fifty-one (51) out of the one hundred and twenty observations of price changes used had cases less than the test value while sixty-eight (68) of the observations had cases more than the test value. The number of runs is 50 . Low number of runs indicates a preponderance of a particular pattern of price changes while a high number of runs indicate interruptions of a particular pattern of price changes by another pattern. The calculated $Z$ value of -1.746 shows that the runs tests was not significant at the $5 \%$ level since the asymptotic significant probability of 0.081 is not less than 0.05 the assumed level of significance, thus implying that successive changes in the prices of stocks traded on the floor of the Nigerian stock Market are random. Here, randomness suggests that price movement on the floor of the Nigerian Stock Exchange does not tend to follow any particular pattern. Results of the runs test are consistent with those revealed by the distribution patterns of stock price changes. In the light of the foregoing, serial correlation test for independence and the runs test for randomness, it is evident that the Nigerian Capital Market is efficient in the weak form since the movement in the prices of shares traded on the floor of the Nigerian stock exchange is random. The results of this study are consistent with Olowe (2002), and Rapuluchukwu (2010); who had earlier conducted similar test using share price data from the Nigerian Stock Exchange. However, the results are inconsistent with the findings of Ekechi (2002) and Inegbedion (2009).

\section{Conclusion}

Based on the above findings, this study concludes that:

*The Past and future prices of stocks traded in the Nigerian Stock market are independent. This finding refutes the technical analysis proposition that assumes relationship between successive share prices of any firm over a study period;

*Successive changes in the prices of stocks traded in the Nigerian Stock market are random. This finding is consistent with the underlying assumption of the Random Walk Theory that security prices are random in an Efficient Market. The implication is that the Nigerian Capital Market is efficient in the weak form because a prerequisite for a weak-form of efficient market is that its security prices follow the Random Walk theory by being random;

The uniqueness of this study is based on the fact that it updated empirical studies on stock price movement and the weak-form of market efficiency in the Nigerian Stock Market; and it used a combination of serial correlation tests and runs tests as the basis for determining "Weak-Form of Market Efficiency" rather than just serial correlation tests as was the case in most previous studies. 


\section{Recommendations}

Evidence from this study shows that changes in the prices of stocks traded on the floor of the Nigerian Stock Exchange are random. This has important implications for the fortune of equity investors. In view of the problem definition and research findings, the following recommendations are suggested:

* There is need for investors to desist from futile attempts at forecasting share prices. Since the Nigerian Capital Market is efficient in the weak form, any new information about any security will cause security prices adjust rapidly to the infusion of such new information. To this end, current stock-prices will, as much as possible, always fully reflect all available information;

* There is need for policy makers to enlighten potential investors of the opportunities that are available in the stock market. Such enlightenment should seek to stimulate their interest in capital market activities and thus increase the breadth and depth of the capital market.

* Given the weak-form efficiency of the Nigerian capital market, increased capital market activities will undoubtedly lead to the enhancement in the allocation of resources since an efficient capital market is instrumental to the efficient allocation of a nation's financial resources.

\section{References}

Agbonifoh, B.A. and Yomere, G.O. (2002), Research Methodology in the Social Sciences and Education, Benin City: Centrepiece Consultancy limited

Aguebor, S.O.N., Adewole, A.P., and Maduegbuna, A.N. (2010), "A Random Walk Model for Stock Market Prices," Journal of Mathematics and Statistics, 6(3): 342-346. http://dx.doi.org/10.3844/jmssp.2010.342.346

Amadi, S.N. and Odubo, T.D. (2002). "Macroeconomic Variables and Stock Prices: Causality Analysis", The Nigerian Journal of Economic and Management Studies, 4(1 \& 2): 30 -39.

Brealy, A.R. and Myers, S.C. (1996). Principles of corporate Finance, New York: McGraw Hill company.

Brumelhuis, R. (2005). Mathematical Methods, Oxford: Birk Beck College press.

Butler, K.C., and Malaikah,S.J. ( 1992). 'Efficiency and Inefficiency in Thinly Traded Stock Markets: Kuwait and Saudi Arabia', Journal of Banking and Finance, 16(2),197-210. http://dx.doi.org/10.1016/0378-4266(92)90085-E

Chan, K.C., Gup, B.E and Ming-Shiun Pan, (1992). 'An Empirical Analysis of Stock Prices in Major Asian Markets and the United States', The Financial Review, 27 (2),289-307. http://dx.doi.org/10.1111/j.1540-6288.1992.tb01319.x

Chen, N. (1991). "Financial Investment Opportunities and the Macroeconomy", Journal of Finance, June: 529-551. http://dx.doi.org/10.2307/2328835

Dickinson, J. P. and Muragu,K. (1994). Market Efficiency in Developing Countries: A Case Study of the Nairobi Stock Exchange. Journal of Business Finance and Accounting, 21(1),133-149. http://dx.doi.org/10.1111/j.1468-5957.1994.tb00309.x

Ekechi, A.O. (2002). "The Behaviour of Stock Prices on the Nigerian stock exchange: Further Evidence," First Bank Quarterly Review, March edition.

El-Erian M. and Kumar, M. ( 1995). 'Emerging Equity Markets in Middle Eastern Countries', IMF Staff Papers, 42(2),313-331. http://dx.doi.org/10.2307/3867575

Fama, E. (1965). "The Behaviour of Stock Market Prices", Journal of Business, Vol. 38, January: 34-49. http://dx.doi.org/10.1086/294743

Fama E.F, (1970). 'Efficient Capital Markets: A Review of Theory and Empirical Work'. Journal of Finance, 25(2), pp.383 - 417. http://dx.doi.org./10.2307/2325486

Fama, E.F. (1995), “Random walks in Stock Market Prices," Finance, Anal J. 21: 55-59. http://dx.doi.org/10.2469/faj.v21.n5.55

Fama,E.F,and French,K.R. (1988). Permanent and Temporary Components of Stock Prices: Journal of Political Economy 96:246-273. http://dx.doi.org/10.1086/261535

Fisher, D.E. and Jordan, R.J. (2005). Security Analysis and Portfolio Management, Partparganji, Delhi: Pearson Education.

Groenewold, N., and Ariff, M. (1998). 'The Effects of De-Regulation on Share-Market Efficiency in the Asia-Pacific', International Economic Journal, 12(4), 23-47. http://dx.doi.org/10.1080/10168739800080027 
Gupta, R, and Basu, P. (2007). "Weak Form Efficiency in Indian stock Markets," International Business and Economics Research Journal, 6: 57-64.

Inegbedion, H.E. (2009). "Efficient Market Hypothesis and the Nigerian Capital Market," an Unpublished M Sc. Thesis written in the Department of Business administration ,University of Benin, Nigeria.

Investor Home. (2008). “The Efficient Market Hypothesis and the Random Walk Theory,” Retrieved November 6, 2008 from file//f/investor-home-The Efficient Market Hypothesis.

Iqbal and Mallikarjunappa, T. (2007). "Market Reaction to Earnings Information: An Empirical Study". Aims International 1(2) 153-167.

Jensen, M. (1978). "Some Anomalies Evidence Regarding Market Efficiency," Journal of Financial Economics, 6: 95-101. http://dx.doi.org/10.1016/0304-405x(78)90025-9

Liu, X., Song, H. and Romilly,P. (1997). 'Are Chinese Stock Markets Efficient? A Cointegration and Causality Analysis', Applied Economics Letters, No.4,511-15. http://dx.doi.org/10.1080/758536636

Lulia,S. (2009). Testing the Efficient Market Hypothesis:A behaviourial approach to the current Economic Crisis.An Unpublished senior honors thesis,Department of Economics,University of California,Berkeley

Maku, O.E.and Atanda, A.A. (2009). "Do Macroeconomic Indicators Exert Shock on the Nigerian Capital Market?" retrieved May 9, 2009 from http://mpra.ub.unimuenehen.de/17917.

Malkiel, B, (2003). "The Efficient Market Hypothesis and its Critics," Journal of Economic Perspective, 17: 59-82. http://dx.doi.org/10.1257/089533003321164958

Mishra, K. (2009). “Indian Capital Market-Revisiting Market Efficiency,” Indian Journal of Capital Markets, 2: 30-34.

Nigerian Stock Exchange (2005). Factbook, Lagos: Pathway Communications.

Olowe, R. (1999). "Weak Form Efficiency in the Nigerian Stock Market: Further Evidence," African Development Review, 11: 32-41.

Ormos, Mihaley. (2002).”Semi-Strong Form of Market Efficiency in the Hungarian Capital Markets”. International Conference "An Enterprise Odyssey: Economics and Business in the New millennium" 2002, graduate School of Economics and Business, University of Zagreb, Croatia, pp 749-758.

Rapuluchukwu,E.U. (2010). “The Efficient market Hypothesis:Realities from the Nigerian Stock Market” Global Journal of Finance and Management 2(2):321-331.

Reilly,F.K. (1989). Investment Analysis and Portfolio Management,Hinsdale,Illinois:Dryden Press.

Samuels, J.M and Wilkes,R. (1981). Management of Company Finance, Lagos: Thomas Nelson Smith, G. (1990). Investments, London: Glenview.

Urrutia, J.L. (1995). 'Tests of Random Walk Efficiency for Latin American Emerging Equity Markets', Journal of Financial Research, 18(3),299-313.

Wikipedia. (2007). "Efficient Market Hypothesis," Retrieved January 16, 2011, http://enwikipedia.org_wiki.efficientmarkethypothesis.

Yalama, A. and Selik, S. (2008). "Financial Market Efficiency in Turkey: Empirical Evidence from Toda Yamamoto causality Test". European Journal of Economics, Finance and Administrative Sciences. Issue: 13. 


\section{Appendix}

Table 1. Nigerian Stock Exchange All-Share Index $\quad$ Month end Values $(2001-2010)$

\begin{tabular}{|l|l|l|l|l|l|l|l|l|l|l|}
\hline MONTH & $\mathbf{2 0 0 1}$ & $\mathbf{2 0 0 2}$ & $\mathbf{2 0 0 3}$ & $\mathbf{2 0 0 4}$ & $\mathbf{2 0 0 5}$ & $\mathbf{2 0 0 6}$ & $\mathbf{2 0 0 7}$ & $\mathbf{2 0 0 8}$ & $\mathbf{2 0 0 9}$ & $\mathbf{2 0 1 0}$ \\
\hline JAN & 8794.2 & 10650 & 13298.8 & 22712.9 & 23073.79 & 23679.44 & 36784.51 & 58570.55 & 21813.76 & 22594.9 \\
\hline FEB & 9180.5 & 10581.9 & 13668.8 & 24797.4 & 21953.5 & 23842.99 & 40730.71 & 65652.38 & 23377.14 & 22985 \\
\hline MAR & 9159.8 & 11214.4 & 13531.1 & 22896.4 & 20682.37 & 23336.6 & 43456.14 & 63015.56 & 19851.89 & 25966.25 \\
\hline APR & 9591.6 & 11399.1 & 13448 & 25793 & 21961.7 & 23301.22 & 47323.99 & 59440.91 & 21491.11 & 26453.2 \\
\hline MAY & 10253.8 & 11486.7 & 14086.3 & 27730.8 & 21482.08 & 24745.66 & 49930.19 & 58929.02 & 29700.24 & 26183.21 \\
\hline JUNE & 10937.3 & 12440.7 & 14565.5 & 28887.4 & 21564.78 & 26161.15 & 51330.46 & 55949 & 26861.55 & 25384.14 \\
\hline JUL & 10576.4 & 12458.2 & 13962 & 27062.1 & 21911 & 27880.5 & 53021.68 & 53110.91 & 25286.61 & 24286.62 \\
\hline AUG & 10320 & 12327.9 & 15426 & 23774.3 & 22935.36 & 33096.37 & 50291.09 & 47789.2 & 23009.1 & 24268.24 \\
\hline SEP & 10274.2 & 11811.6 & 16500.5 & 22739.7 & 24635.91 & 32554.6 & 50229.01 & 46216.13 & 22065 & 28223.43 \\
\hline OCT & 11091.4 & 11811.6 & 18743.5 & 23354.8 & 25873.81 & 32643.68 & 50201.82 & 36325.86 & 21804.69 & 25042.16 \\
\hline NOV & 11169.6 & 11622.7 & 19319.3 & 23270.5 & 24355.85 & 31632.54 & 54189.92 & 33025.75 & 21010.29 & 25000 \\
\hline DEC & 10963.1 & 12137.7 & 20128.9 & 23844.5 & 24085.76 & 33189.3 & 57990.22 & 31450.78 & 20827.17 & 24770.52 \\
\hline
\end{tabular}

Source: Nigerian Stock Exchange Fact book (2010).

\section{NON PARAMETRIC TESTS}

Table II. Runs Test for Randomness of share price data

\begin{tabular}{|l|c|}
\hline & DIFF (VAR 000002,1) \\
\hline TEST VALUES & -97.7462 \\
Cases Test Value & 51 \\
Cases $\geq$ Test value & 68 \\
Total Cases & 119 \\
Number of Runs & 52 \\
Z & -1.748 \\
Asymp. Sig. (2-tailed) & 0.081 \\
\hline
\end{tabular}

Table III. Summary of Results of First Order Serial Correlation of Month end Changes in the All Shares Index of the Nigerian stock Exchange (JAN 2001 - 2010)

\begin{tabular}{|l|l|l|l|l|l|}
\hline LAG & \multirow{2}{*}{ AUTOCORRELATION } & STD & \multicolumn{3}{|c|}{ BOX-LJUNG STATISTIC } \\
\cline { 4 - 6 } & & ERROR & VALUE & DF & SIG. \\
\hline 1 & 0.066 & 0.092 & 0.532 & 1 & 0.466 \\
\hline 2 & -0.036 & 0.092 & 0.688 & 2 & 0.709 \\
\hline 3 & -0.58 & 0.092 & 1.109 & 3 & 0.775 \\
\hline 4 & 0.045 & 0.092 & 1.364 & 4 & 0.850 \\
\hline 5 & 0.065 & 0.093 & 1.896 & 5 & 0.863 \\
\hline 6 & -0.097 & 0.093 & 3.096 & 6 & 0.797 \\
\hline 7 & -0.175 & 0.094 & 7.044 & 7 & 0.424 \\
\hline 8 & 0.027 & 0.097 & 7.140 & 8 & 0.522 \\
\hline 9 & -0.136 & 0.097 & 9.564 & 9 & 0.387 \\
\hline 10 & -0.084 & 0.098 & 10.503 & 10 & 0.398 \\
\hline 11 & -0.076 & 0.099 & 11.271 & 11 & 0.421 \\
\hline 12 & 0.087 & 0.099 & 12.285 & 12 & 0.423 \\
\hline 13 & 0.046 & 0.100 & 12.576 & 13 & 0.481 \\
\hline 14 & 0.068 & 0.100 & 13.214 & 14 & 0.510 \\
\hline 15 & 0.107 & 0.101 & 14.799 & 15 & 0.466 \\
\hline 16 & 0.064 & 0.102 & 15.376 & 16 & 0.497 \\
\hline
\end{tabular}




\section{Autocorrelations}

\begin{tabular}{|c|c|c|c|c|c|}
\hline \multirow[b]{2}{*}{ Lag } & \multirow[b]{2}{*}{ Autocorrelation } & \multirow[b]{2}{*}{ Std. Error ${ }^{a}$} & \multicolumn{3}{|c|}{ Box-Ljung Statistic } \\
\hline & & & Value & df & Sig. ${ }^{b}$ \\
\hline 1 & .067 & .092 & .543 & 1 & .461 \\
\hline 2 & -.043 & .092 & .770 & 2 & .681 \\
\hline 3 & -.052 & .092 & 1.111 & 3 & .774 \\
\hline 4 & -.042 & .092 & 1.334 & 4 & .856 \\
\hline 5 & -.062 & .093 & 1.826 & 5 & .873 \\
\hline 6 & -.100 & .093 & 3.105 & 6 & .796 \\
\hline 7 & -.185 & .094 & 7.486 & 7 & .380 \\
\hline 8 & .033 & .097 & 7.631 & 8 & .470 \\
\hline 9 & -.138 & .097 & 10.141 & 9 & .339 \\
\hline 10 & -.082 & .099 & 11.019 & 10 & .356 \\
\hline 11 & -.078 & .099 & 11.837 & 11 & .376 \\
\hline 12 & .124 & .100 & 13.919 & 12 & .306 \\
\hline 13 & .042 & .101 & 14.153 & 13 & .363 \\
\hline 14 & .080 & .101 & 15.030 & 14 & .376 \\
\hline 15 & .069 & .102 & 15.685 & 15 & .403 \\
\hline 16 & .084 & .102 & 16.664 & 16 & .408 \\
\hline
\end{tabular}

a. The underlying process assumed is MA with the order equal to the lag number minus one. The Bartlett approximation is used.

b. Based on the asymptotic chi-square approximation. 